\title{
CONTEXTO GEOPOLÍTICO GLOBAL, RIESGOS Y COBERTURA A TRAVÉS DE SEGUROS*
}

\author{
GEOPOLITICAL GLOBAL CONTEXT, \\ RISKS AND INSURANCE COVERAGE
}

\author{
VICENTE RÍOS URZÚA ** \\ Fecha de recepción: 12 de abril de 2021 \\ Fecha de aceptación: 30 de mayo de 2021 \\ Disponible en línea: 30 de junio de 2021
}

Para citar este artículo/To cite this article

Rios URzúA, Vicente. Contexto geopolítico global, riesgos y cobertura a través de seguros, 54 Rev.Ibero-Latinoam.Seguros, 15-40 (2021).

https://doi.org/10.11144/Javeriana.ris54.cggr

doi:10.11144/Javeriana.ris54.cggr

\footnotetext{
Texto expositivo que surge del interés del autor por realizar una revisión panorámica respecto de lo que se entiende por riesgo político y los mecanismos de transferencia actualmente comercializados por la industria aseguradora para extender cobertura a dicha categoría de riesgo asegurable. En ese sentido, se abordan definiciones de sentido y alcance respecto de la noción de Riesgos Políticos y sus diversas líneas de cobertura.

** Abogado, Licenciado en Ciencias Jurídicas y Sociales, Universidad Adolfo Ibáñez (Chile). Master in Business Law, LL.M. UAI. Diplomado en Derecho Administrativo mención Derecho Económico, Universidad Católica de Chile (PUC). Miembro de la Asociación Internacional de Derecho de Seguros (AIDA). Miembro del Instituto Iberoamericano de Derecho Marítimo (IIDM). Legal \& Insurance Manager en Liventus S.A., y Socio en RO Abogados. Orcid: https://orcid.org/0000-0002-8655-4607. Contacto: vrios@roabogados.com
} 


\title{
RESUMEN
}

La globalización ha devenido en integración económica, cultural, social y política. Una forma de manifestación evidente de dicha realidad ha sido el constante aumento de proyectos de inversión que involucran a inversionistas de múltiples naciones y a países que poseen economías emergentes o en vías de desarrollo. Un elemento esencial para la seguridad de dicho tipo de inversión es la estabilidad normativa y la previsibilidad regulatoria de la economía que recibe la inversión extranjera, sin embargo, hay realidades sociales y geopolíticas que muchas veces plantean desafíos para el mantenimiento de aquel necesario estándar de certeza y confianza. Los cambios o alteraciones en las condiciones normativas representan riesgos y, dado ese contexto, los inversionistas han debido diseñar estrategias de mitigación o transferencia, surgiendo soluciones desde la industria aseguradora que es necesario entender para diseñar correctas definiciones de inmersión en nuevos mercados.

Palabras clave: Riesgos políticos, Seguros, Geopolítica, Riesgo Asegurable, Orden Público, Comercio Internacional.

\begin{abstract}
Globalization has resulted in economic, cultural, social and political integration. One form of evident manifestation of this reality has been the constant increase in investment projects that involve investors from multiple nations and countries with emerging or developing economies. An essential element for the security of this type of investment is the regulatory stability and normative predictability of the economy that receives foreign investment, however, there are social and geopolitical realities that pose challenges for maintaining that necessary standard of certainty and trust. Changes or alterations in regulatory conditions represent risks and, given this context, investors have had to design mitigation or transfer strategies, emerging solutions from the insurance industry that must be understood by the insurers in order to design correct definitions of immersion in new markets.
\end{abstract}

Keywords: Political Risks, Insurance, Geopolitics, Insurable Risk, Public Order, International Trade. 


\section{SUMARIO}

1. Introducción: contexto geopolítico actual. 2. Definición de riesgo político en materia de seguros. a. Sobre la definición de Riesgo, en general, y Riesgo Asegurable ${ }^{1}$, en particular. b. Noción de Orden Público y definición riesgos políticos o antisociales. c. Relevancia para el comercio internacional: dimensión legal y financiera. 3. Sobre las cláusulas que extienden cobertura a riesgos políticos. a. Póliza de Riesgos Políticos (PRI, por sus siglas en inglés): categorías de riesgos políticos habitualmente cubiertos. b. Otros seguros que extienden cobertura a riesgos políticos y sus redacciones habituales. i. Seguros de Crédito y Garantía. ii. Seguros de Incendio. iii. Seguros de Huelga y Pérdidas por Paralización. iv. Seguros marítimos y de comercio internacional. c. Tipos de proveedores de seguros de riesgos políticos. 4. Desafíos para la industria. a. Perspectiva General. b. Perspectiva desde la Industria Aseguradora. 5. Conclusiones. 6. Bibliografía.

${ }^{1}$ No es objeto del presente estudio generar un análisis acabado sobre la definición de Riesgo Asegurable, su conceptualización y/o características. Sin embargo, hacemos presente al lector que podrán encontrar líneas académicas sobre esta materia en los siguientes artículos: 1) Ríos Ossa, Roberto (2010). "Modificación al Código de Comercio Chileno: Artículo 513 inciso segundo -El Riesgo-". Revista Chilena de Derecho, vol. 37 N 3, pp. 505-520. Santiago, Chile. 2) Ríos Urzúa, Vicente (2017). "Noción de riesgo asegurable: la importancia de identificar un riesgo atípico". Revista Chilena de Derecho de Seguros, Año 19, № 26, pp. 99-112. Santiago, Chile. 


\section{INTRODUCCIÓN: CONTEXTO GEOPOLÍTICO ACTUAL}

La vida en sociedad deviene en constantes evoluciones económicas, políticas y sociales. Esta es una realidad que difícilmente podríamos soslayar, menos aun considerando que la globalización y la cada vez mayor integración y dependencia económica entre las naciones acentúan día a día ese sentido de interdependencia que gobierna el actual escenario mundial.

De la globalización e interdependencia descritos surgen escenarios múltiples de interacción, sin embargo, parece ser que es la actividad económica la que termina por otorgar una realidad unificadora en torno a las expectativas de la sociedad toda. Expresión de esto es que organismos internacionales, tales como el Fondo Monetario Internacional (IMF, por sus siglas en inglés), entregan anualmente perspectivas de desarrollo económico mundial, identificando aquellos factores de riesgo y/o incertidumbre que pudieren afectar las expectativas de desarrollo económico desde una mirada global. Así, en el Informe de Perspectivas de la Economía Mundial de enero de 2021, se menciona que "la reciente aprobación de vacunas ha alentado la esperanza de que la pandemia llegue a un punto de inflexión más adelante en el año, pero las nuevas olas y variantes del virus generan inquietudes acerca de las perspectivas. En medio de esta excepcional incertidumbre, se proyecta que la economía mundial crezca 5,5\% en 2021 y 4,2\% en 2022 "2.

Lo previamente citado se lee como alentador, desde una mirada social y financiera, pero desde un análisis geopolítico, da cuenta de que la geografía de la vida (desde la perspectiva física y humana) está radicada en el mundo como una ubicación cada vez más común, en el sentido de representarse como un espacio de interacción política, social, económica y cultural que resulta cada vez más complejo desagregar. Es así como nos encontramos con una realidad económica que actualmente basa sus pilares en las relaciones comerciales internacionales y que, por cierto, confía el éxito de dichas empresas a la estabilidad que las naciones partícipes puedan proveer.

No son pocos los eventos que pueden terminar por afectar la estabilidad que todo actor económico anhela para la concreción de sus proyecciones financieras y el éxito de sus negocios. Así, la pandemia derivada del virus SARS-CoV-2 (COVID19) ha venido a demostrar que existe un sistema financiero global que puede sucumbir ante imprevistos de cualquier naturaleza, incluidos, por cierto, eventos sanitarios que podríamos pensar que para el siglo XXI ya deberían ser un riesgo totalmente mitigado.

Existen otros eventos que también reúnen las condiciones de magnitud como para afectar la estabilidad económica, política y/o social de una nación o de una región completa. Son ejemplos de esto la denominada (por algunos autores) "crisis civilizatoria y de paz" en Colombia ${ }^{3}$; el "estallido social" ocurrido en Chile durante

\footnotetext{
2 "Informe de Perspectivas de la Economía Mundial", enero 2021. Fondo Monetario Internacional. Recurso on-line. URL: https:/www.imf.org/es/Publications/WEO/Issues/2021/01/26/2021. Última visita: 09 de abril de 2021.

3 Roncancio J., Germán (2014). "Contexto Geopolítico, Globalización, Crisis Civilizatoria y Paz en Colombia". Artículo de Investigación, publicado en El Ágora USB, Universidad de San Buenaventura Medellín. V. 14, No 2, Junio - Diciembre. PP. 439. Medellín, Colombia.
} 
octubre de 2019 y que devino en un movimiento social de masas que, entre otras cosas, desencadenó un proceso constituyente, además de producir un freno en el crecimiento económico, una reducción en la recaudación fiscal y una fuerte contracción en las proyecciones financieras del país ${ }^{4}$; o, los episodios de bloqueos comerciales entre EE.UU. y China; entre otros casos de similar naturaleza.

En términos prácticos, los eventos mencionados significan sucesos que muchas veces impiden la concreción de negocios, la ejecución de contratos y/o, en general, el cumplimiento de obligaciones entre partes que pueden ser de nación común o de distintos países. Claramente pueden existir remedios contractuales que prevean escenarios de imposibilidad sobreviniente, pero ello no necesariamente va a cumplir con resarcir los daños o perjuicios que sufra la parte cumplidora. Es más, muy probablemente las particularidades de un negocio permitan distinguir entre eventos de caso fortuito y fuerza mayor que pudieren impedir la concreción de una operación financiera particular, pero aquello podría ser insuficiente si nos encontramos con eventos sociales o políticos completamente imprevistos para un escenario de estabilidad democrática media.

Es así como surge, en tanto riesgo, la posibilidad de ocurrencia de eventos derivados de decisiones de gobierno, lo que deberíamos denominar riesgo político propiamente tal, además de otros eventos de desorden social o calamidad pública que tengan origen en factores sociales, legales, económicos o puramente políticos, que pueden efectivamente mermar o anular las posibilidades de concreción de un negocio. Estos riesgos han sido reconocidos por la industria aseguradora a través de distintas acepciones, las que analizaremos en este texto, buscando descubrir sus ámbitos de cobertura y aplicación, y las formas o mecanismos de calificación que la misma industria ha diseñado.

\section{DEFINICIÓN DE RIESGO POLÍTICO EN MATERIA DE SEGUROS}

\section{a. Sobre la definición de Riesgo, en general, y Riesgo Asegurable ${ }^{5}$, en particular}

En términos puramente semánticos, el vocablo riesgo evoca la probabilidad de que ocurra algo que tiene una connotación eminentemente negativa en términos de devenir

\footnotetext{
${ }^{4}$ Artículo de prensa titulado: "Protestas en Chile: las consecuencias económicas y de imagen de la cancelación de 2 grandes cumbres internacionales por el estallido social”, publicado por BBC. Disponible on-line: https://www.bbc.com/mundo/noticias-50241141. Última visita: 12 de abril de 2021.

5 No es objeto del presente estudio generar un análisis acabado sobre la definición de Riesgo Asegurable, su conceptualización y/o características. Sin embargo, hacemos presente al lector que podrán encontrar líneas académicas sobre esta materia en los siguientes artículos: 1) Ríos Ossa, Roberto (2010). "Modificación al Código de Comercio Chileno: Artículo 513 inciso segundo -El Riesgo-". Revista Chilena de Derecho, vol. $37 \mathrm{~N}^{\circ} 3$, pp. 505- 520. Santiago, Chile. 2) Ríos Urzúa, Vicente (2017). "Noción de riesgo asegurable: la importancia de identificar un riesgo atípico". Revista Chilena de Derecho de Seguros, Año 19, N 26, pp. 99-112. Santiago, Chile. Publicación de la Asociación Internacional de Derecho de Seguros, sección chilena.
} 
en daños, perjuicios, desgracia o sufrimiento. La doctrina relevante en la materia indica, al referirse a la noción de riesgo, que se puede definir como "una eventualidad desfavorable de un daño o de verificarse un hecho económicamente perjudicial en la esfera jurídica y económica de un sujeto. Se trata del elemento fundamental del contrato de seguros o, más aún, el presupuesto esencial para la existencia de una válida relación asegurativa"’6.

Es claro que para los seguros no interesa tanto la noción semántica de riesgo, puesto que no toda ocurrencia en sí misma puede ser asegurada. Nos va a interesar, entonces, aquella descripción de riesgo asegurable en términos técnicos.

El riesgo asegurable se presenta como un elemento básico en el contrato de seguros, pero no sólo por ser un elemento puramente caracterizador del contrato, sino también por tratarse de una circunstancia de hecho que según sea su intensidad, probabilidad de ocurrencia o extensión económica, será lo que definirá, por un lado, la prima o contraprestación que se establecerá de cargo del Asegurado, así como el monto asegurado total o, en definitiva, la máxima exposición que el Asegurador decida asumir. Por lo tanto, la doble dimensión (económica y jurídica) del concepto emana desde su misma conceptualización, siendo necesario mantener presente este doble carácter si se busca analizar la evolución teórica y regulatoria de la noción de riesgo asegurable.

En el caso de la legislación chilena, encontramos una definición legal de lo que se debe entender como riesgo en materia de seguros, contenida en el art. 513 letra t) del Código de Comercio (en adelante, C. de Com.) donde se lee: "Art. 513. Definiciones. Para los efectos de la normativa sobre seguros se entenderá por: t) Riesgo: la eventualidad de un suceso que ocasione al asegurado o beneficiario una pérdida o una necesidad susceptible de estimarse en dinero". Esta definición viene a describir un elemento que el Art. 512 del mismo cuerpo normativo eleva a esencial para el contrato de seguros, e, inclusive, para la propuesta (cotización) de contrato, tal como se lee en el Art. 514.

Usando como base lo indicado, y siguiendo a parte relevante de la doctrina en la materia, podemos aseverar que del análisis de esta y otras descripciones logramos obtener una caracterización multidimensional del concepto de riesgo asegurable, en el sentido que debe ser: (1) Consecuencia de un pacto expreso y delimitado, (2) Que permite incluir la asunción de riesgos provenientes de conductas culposas del asegurado, lo que queda sujeto al contexto de las negociaciones asociadas al riesgo que se busca transferir y la cuota que esté dispuesto a asumir el tercero asegurador; (3) Que debe ser posible, es decir, que debe existir una eventualidad o contingencia futura de ocurrencia probable, y (4) Que de ocurrir el hecho, no exista intervención dolosa del Asegurado en dicha ocurrencia, lo que se ha venido a reforzar a través de la aparición de la figura del fraude al seguro?

\footnotetext{
6 VÁsquez P., María Fernanda (2019). Contrato de Seguros: Doctrina y Jurisprudencia. Editorial Tirat lo blanch, Valencia, España, p. 68.

7 En este sentido, la Ley 20.667 vino a complementar la regulación existente en orden a incorporar nociones descriptivas derivadas del principio Uberrima Bona Fides, base sobre la cual se erige la confianza en la que se funda la transferencia de riesgos en el contrato de seguros. Detalles respecto de los aportes de esta
} 


\section{b. Noción de Orden Público y definición de riesgos politicos o antisociales}

Si hiciéramos un parangón, la estabilidad y/o previsibilidad de las reglas del juego es a la industria financiera lo que es el Orden Público es al derecho. Es decir, son conceptos que evocan, en ambas disciplinas, nociones de confianza.

Si quisiéramos definir la idea general de Orden Público, sin ser el objeto del presente estudio generar debate sobre la idea general $^{8}$, deberíamos afirmar que se entiende como aquel conjunto de condiciones y/o factores esenciales para la vida en sociedad y que encuentran su origen en instituciones de naturaleza jurídica establecidas en un esquema legislativo nacional. Estas condiciones y/o factores esenciales son justamente declaraciones que permiten organizar la comunidad en base a criterios que no pueden ser alterados arbitrariamente ni por los individuos ni por las autoridades, salvo que dicho cambio o modificación emane justamente de procesos jurídicamente válidos, tales como el proceso de formación de ley por iniciativa social, parlamentaria y/o presidencial, según el sistema o la materia respecto de lo que verse el cambio deseado.

Lo dicho ciertamente obedece a una aproximación parcial al concepto de fondo. De hecho, podríamos en principio afirmar que la descripción propuesta es más bien propia de una idea de Orden Público Interno, en contraposición a lo que algunos autores denominan Orden Público Internacional ${ }^{9}$. En cualquier caso, es posible aseverar que la idea de Orden Público conlleva la noción de protección del "interés general", entendido como el apego a aquella conducta social que cumpla con las pretensiones de justicia, seguridad y estabilidad que la vida en sociedad requiere.

Bajo ciertas realidades sociales ocurrirá que la noción de Orden Público previamente planteada se transforme en un deseo más que en una realidad. Chile, por ejemplo, gozaba de cierta reputación de país estable en términos sociales y de crecimiento económico, idea que se fue reforzando con el pasar de los años, particularmente a

Ley en Carvajal A., Lorena y Mayer L., Laura (2015). El Nuevo Fraude de Seguros. Artículo académico, Revista de Derecho de la Universidad Católica del Norte, Chile, pp. 280 y ss.

8 Es sabido que la determinación del concepto de Orden Público es un tema que ha ocupado a la doctrina desde hace mucho. Así lo mencionan algunos autores, al indicar a modo ejemplar que "Nusebaun da una breve reseña de la noción de orden público en un antiquísimo papiro del siglo II d. de C, según el cual un juez rechaza la aplicación del derecho egipcio sobre la dote por considerarlo inhumano. Asimismo, encontramos antiguos axiomas clásicos, tales como el "Digesto. Privatorum conventio iuris publicum non derogat" (las convenciones particulares no pueden derogar el derecho público), que reflejan el concepto de orden público relacionado con el Derecho Público utilizado en la antigüedad y que en muchas legislaciones modernas se sigue utilizando". En: Márquez G. Stephanie. (2009). "El Orden Público y su función como límite a la eficacia, reconocimiento y ejecución de los laudos arbitrales internacionales en Chile". Tesis para optar a grado de Magíster. Universidad de Chile. Santiago, Chile. Recurso disponible on-line, en: http:// repositorio.uchile.cl/bitstream/handle/2250/110957/de-marquez_s.pdf;sequence=1, pp. 10-11. Última visita: 10.04 .2021 .

9 Tal como se mencionó, no es objetivo del presente trabajo aportar líneas críticas sobre la conceptualización de la noción de Orden Público. Sin embargo, dicha materia es de suma relevancia para el Derecho Privado, tal como lo anticipó el profesor Roldán Pardo en el siguiente artículo: Roldán P. Juan F. (2010). “El estado del arte del concepto de Orden Público Internacional en el Ámbito del Derecho Internacional Privado y el Arbitraje Internacional'. Revista de Derecho Privado N 44, Julio - Diciembre de 2010. Universidad de los Andes, Bogotá Colombia. 
partir de 1990 con el término del Gobierno Militar y la asunción de un gobierno democráticamente elegido. Sin embargo, múltiples causas devinieron en marchas sociales que tuvieron punto cúlmine el 18 de octubre de 2019 (18-O, tal como la prensa lo llama), fecha en la que las marchas pasaron a transformarse en protestas violentas, saqueos, incendio de mobiliario público y privado, todos calificables como de desorden popular, entre varios otros hechos que terminaron por obligar al gobierno de turno a decretar el Estado Constitucional de $\mathrm{Sitio}^{10}$, restringiendo el libre desplazamiento de las personas a través del establecimiento de toques de queda y movilizando personal militar a las calles.

Lo narrado, además de representar un hito sociológico que ciertamente requiere un necesario análisis, constituye un claro ejemplo de hechos de connotación pública que poseen la aptitud suficiente como para alterar la noción de Orden Público discutida, destruyendo por un periodo de tiempo determinado (o indeterminado) aquella estabilidad que hacía posible la concreción de negocios, el desarrollo financiero del país, y, en concreto, la ejecución de aquellos actos o contratos válidamente celebrados entre partes que no pudieron prever el estado de calamidad pública que acaecería, sin previo aviso, esa noche del 18 de octubre en Chile.

Siguiendo con el ejemplo, podemos decir que aquella "reputación de país estable" que Chile poseía ciertamente se alteró. De hecho, prensa especializada de la época ya describía la nueva realidad como una sombría, indicando en enero de 2020, al proyectar un nuevo año, que "los más afectados (por la violencia de octubre y los días posteriores) son los que tienen sus negocios cercanos a la "zona cero", que, si no están pensando en cerrar definitivamente, sí lo están en asegurarse ante el vandalismo y ante al llamado "riesgo político". Estos son los seguros que ellos necesitarán"1". Estas líneas nos describen cómo se afectó la idea de Orden Público y, a su vez, cómo ello tiene un inmediato impacto en las perspectivas de asegurabilidad de hechos que antes de lo ocurrido no representaban un riesgo con probabilidad real de ocurrencia.

En el ejemplo dado y/o de otras realidades asimilables podemos encontrar variadas casuísticas de hecho que, en lo material, devengan en una alteración del Orden Público. Hecho tales como el desorden popular, manifestaciones, saqueos, incendio, guerra civil, revolución, disturbios, terrorismo y/o, en general, los daños intencionados, se podrían entender como factores de alteración del Orden Público.

Sin embargo, de los conceptos dados, podemos visualizar diferencias que, en principio, nos exponen a riesgos políticos (en lo literal del vocablo) pero que tienen puntos de origen y efectos que pueden ser muy disímiles. Así, por ejemplo, una manifestación pública que concluye con incendio de uno o más locales comerciales no implica necesariamente un riesgo de una magnitud equiparable con un evento que derive en

\footnotetext{
${ }_{10}$ Aquel que procede en casos de grave conmoción interior o de guerra civil, pudiendo ser declarado por el Presidente de la República con aprobación del Congreso. Art. 40 número 2 de la Constitución Política de Chile.

${ }^{11}$ Artículo de presenta titulado: "Coberturas por riesgos políticos, vandalismos e incendios podrían aumentar este año", publicado por medio El Economista América. Recurso on-line: https://www. eleconomistaamerica.cl/empresas-eAm-chile/noticias/10297895/01/20/Coberturas-por-riesgos-politicosvandalismos-e-incendios-podrian-aumentar-este-ano.html. Última visita: 12.04.2021.-
} 
guerra civil. Al menos, en lo práctico, no deberíamos esperar reacciones de gobierno similares en uno u otro caso.

Resulta, entonces, relevante para los efectos de estudio diferenciar en atención ámbito de afectación del riesgo, debiendo distinguir entre Riesgos políticos de connotación nacional y Riesgos políticos de connotación internacional. Los primeros serán aquellos que tienen un ámbito geográfico de ocurrencia local o regional, distinguiéndose de los segundos dado que no alcanzan a generar una esfera o radio de afectación que involucre terceras partes o naciones.

En segundo término, proponemos también distinguir en atención a la naturaleza u origen del riesgo, diferenciando entre los Riesgos políticos de origen social, entendidos como aquellos que surgen de movimientos populares radicados en los nacionales de un país o sector, y los Riesgos políticos propiamente tales, que serían aquellos que surgen de la Administración Pública de una nación y/o sus agentes, y que se traduce en un efecto que altera el normal funcionamiento de la administración y de su relación con terceros, ya sean privados u otras naciones.

En tercer término, debemos también clasificar el riesgo en términos de duración o vigencia, existiendo Riesgos políticos de corta duración, entendidos como aquellos que se circunscriben a un evento particular sin permanencia ni continuidad temporal, y los Riesgos políticos de larga duración, entendidos como aquellos que, por su compleja realidad material, tienen sentido de permanencia $\mathrm{y} / \mathrm{o}$, eventualmente, duración indeterminada.

Las categorías propuestas nos permiten arribar a una idea general de lo que debemos entender por Riesgo Político, puesto que lo podríamos definir como aquellas acciones o inacciones de connotación popular que afectan la estabilidad del Orden Público en un contexto dado. La amplitud de la definición propuesta nos permite comprender que no todo Riesgo Político va a ser asegurable per se, de hecho, para arribar a la noción asegurable del concepto, la industria ha incorporado variables económicas, financieras y administrativas, indicando que son Riesgos políticos Asegurables aquellas acciones o inacciones de un gobierno (propio o extranjero) que, por su naturaleza, pueden afectar el desarrollo de proyectos e inversiones ${ }^{12}$. Son ejemplos de eventos materiales calificables como riesgos políticos, los siguientes:

i. Disposición arbitraria de bienes físicos identificables como activos debido a actos de terrorismo, hipótesis de guerra civil y/o cualquier otra forma asimilable de violencia política.

ii. Confiscación, expropiación, nacionalización y privación de activos físicos o inversiones de capital provenientes de nacionales o capitales extranjeros, incluidas otras naciones.

\footnotetext{
12 Diversos actores de la industria aseguradora describen los seguros de Riesgos Políticos de la manera indicada, tal como se lee en la página corporativa de Aon Benfield, al identificar la cartera de productos disponibles. Recurso on-line: https:/www.aon.com/spain/productos_servicios/consultoria-gestion-riesgos/ credito.jsp. Última visita: 12.04.2021.-
} 
iii. Desinversión forzada de inversión extranjera por orden del gobierno local del inversionista.

iv. Cancelación ilícita y/o arbitraria por parte del gobierno o la administración de permisos, licencias o concesiones, afectando el principio de confianza que regula las relaciones entre privados y la administración.

v. Daño físico a los activos debido a la violencia política, incluida la guerra, y las pérdidas resultantes de los ingresos del negocio.

vi. Frustración o cancelación del contrato debido a incumplimiento por parte del gobierno $\mathrm{u}$ otros actos gubernamentales.

vii. Bloqueo de los flujos de efectivo transfronterizos debido a la inconvertibilidad de la moneda y la no transferencia.

viii. Restricciones de exportación o importación que impidan el cumplimiento de contratos válidamente celebrado y que, en consecuencia, causan pérdidas financieras en las transacciones comerciales vigentes.

ix. No honrar un laudo arbitral por parte de una entidad gubernamental (incumplimiento de contrato).

x. Falta de pago de la deuda por parte de una entidad privada.

Así las cosas, podemos afirmar que los riesgos políticos que asegura la industria son aquellos: i) de connotación nacional o internacional; ii) principalmente de origen administrativo o gubernamental (Aquellos riesgos que hemos definido como riesgos políticos propiamente tales); iii) de gravedad, en términos de magnitud, suficiente como para tener sentido de permanencia o duración indeterminada; y, iv) que producen afectación económica o inestabilidad financiera, afectando a terceros privados u otras naciones.

Se podría concluir que todos los eventos que no se acerquen a la caracterización dada no serán, en esencia, riesgos asegurables a través de una póliza de riesgos políticos. Dado lo anterior, deberíamos excluir de dicha cobertura, por ejemplo, las hipótesis de huelgas o incendios que generan daños físicos locales comerciales. Sin embargo, esta afirmación inicial posee cierta imprecisión. Lo cierto es que los ejemplos mencionados también son calificables como riesgos políticos, sólo que serán aquellos de origen social, de ámbito de ocurrencia eminentemente nacional y de corta duración. Dado lo anterior, estos eventos no serán asegurables a través de una Póliza de Riesgos Políticos propiamente tal, sino que encontrarán cobertura a través de cláusulas adicionales redactadas para tales efectos e incluidas en pólizas de incendio, de pérdida por paralización (PxP), de transporte, u otras, redacciones que analizaremos más adelante.

\section{c. Relevancia para el comercio internacional: Dimensión legal y financiera}

Tal como se ha dicho, una de las condiciones esenciales para la concreción de aquellas transacciones financieras que involucran varios países es la estabilidad de los marcos 
normativos y la previsibilidad de los cambios o de la dirección regulatoria. Dado lo anterior, una manera eficiente de mitigar el impacto financiero que produciría en una transacción internacional un quiebre institucional o un acto grave de violencia política es, en esencia, el contar con cobertura a través de seguros.

En particular, los seguros que se extienden a cubrir hipótesis de riesgos políticos se diseñan para entornos de riesgos complejos y dinámicos. Así las cosas, un seguro de riesgos políticos puede permitir a los inversionistas acercarse a mercados emergentes asociados a países en desarrollo, comprendiendo de mejor manera los riesgos que enfrentaría la empresa y, además, aportando visión estratégica en términos de administración de riesgos, asunción de exposiciones y aprovechamiento de oportunidades financieras.

América del Sur representa justamente el ejemplo de naciones con economías pujantes, pero con realidades regulatorias que no otorgan la seguridad necesaria como para desarrollar grandes inversiones ${ }^{13}$. La doctrina jurídica ha ido desarrollando conceptos que permiten analizar esto desde la perspectiva de la relación Ciudadano-Estado pero que podría también ser extrapolable a la relación Inversionista-Estado. En derecho esto se reconoce como Principio de Confianza Legítima, concepto que dice relación con un sentido de permanencia en la regulación y la aplicación del ordenamiento jurídico vigente. Este principio deviene como un límite para la actuación del estado o la administración pública y, en contrapartida, representa para los ciudadanos una noción de amparo y protección.

Este es un principio diseñado por la doctrina del Derecho Administrativo pero que en Chile encuentra sustento en los principios de legalidad (arts. 5, 6 y 7 de la Constitución Política de Chile, en adelante, CPR) y de seguridad jurídica (art. $19 \mathrm{~N}^{\circ} 26 \mathrm{CPR}$ ). La doctrina indica que a través de estos principios debemos entender que "le está vedado a la Administración Pública actuar en ejercicio de sus potestades de manera abusiva (arbitraria) o en exceso de poder. Es precisamente en el primer caso, el del abuso en el ejercicio de potestades, el de la arbitrariedad, comprendidos dentro del principio de legalidad en sentido amplio, en que la Administración deberá motivar y señalar las razones para su actuación. Si tal actuación supone una alteración en la interpretación de la norma o un cambio en la manera de regular o de resolver, solo estará legítimamente autorizada para hacerlo, si respeta, entre otros, la confianza que los administrados tienen en su forma o dirección de la actuación "14.

\footnotetext{
13 Hechos como los ocurridos en Chile con el "Estallido Social" durante el 2019, o los ocurridos en Perú con los sucesivos cambios de gobierno durante el 2020 no son aislados. De hecho, algunos autores también mencionan a Colombia: "Political risk is one of the risks that foreign investors fear the most when investing in Colombia. Such risk is related to security concerns, and may be evidenced through changes in policy, legislation, contractual relations with state entities, or economic instability". Morales T., Paola (2005). "Political Risk Insurance and Breach of Contract Coverage: How the Intervention of Domestic Courts May Prevent Investors from Claiming Insurance". Pace International Law Review, Vol. 17, issue II, fall 2005, pp. 303.

14 Bermúdez S. Jorge (2005). "El principio de confianza legítima en la actuación de la administración como límite de la potestad invalidatoria”. Revista de Derecho Vol. XVIII - N² 2 - Diciembre 2005 Páginas 86-87. Santiago, Chile.
} 
De lo expuesto resulta claro poder concluir que existe una directa y natural relación entre la confianza en las instituciones, dicho desde una perspectiva legal, y el desarrollo de la inversión extranjera, existiendo mayores posibilidades de acoger grandes proyectos económicos en aquellas naciones que son capaces de proveer mayor estabilidad en las reglas del juego. En ese escenario, y en caso de existir un evento que afecten dicha estabilidad política, los seguros juegan un rol clave.

\section{SOBRE LAS CLÁUSULAS QUE EXTIENDEN COBERTURA A RIESGOS POLÍTICOS}

En el siguiente acápite nos enfocaremos en identificar las formas de cobertura de riesgos políticos que actualmente existen en el mercado asegurador. Comenzaremos analizando la matriz de cobertura esencial que viene dada por la Póliza de Riesgos Políticos propiamente tal. Luego, analizaremos las diversas formas de cobertura para riesgos políticos contenidas en pólizas de diversas naturalezas a través de cláusulas especiales o adicionales.

\section{a. Póliza de Riesgos Políticos (PRI, por sus siglas en inglés): categorias de riesgos politicos habitualmente cubiertos}

La póliza de Riesgo Políticos propiamente tal es aquella que se redacta para proteger los intereses de terceros inversionistas, normalmente empresas, frente a acciones o inacciones de gobiernos extranjeros en donde hayan iniciado proyectos financiados con capitales nacionales o foráneos. Lo capital radica en que este tipo de seguro busca cubrir al asegurado en aquellos eventos o incidentes que deriven en suspensiones de pagos, incautación de activos estratégicos o, en general, cambio en las condiciones regulatorias que impiden la estabilidad de la inversión iniciada.

En un origen, estos seguros eran tomados por grandes instituciones financieras, principalmente bancos, y tenían por objeto primordial cubrir riesgos de incertidumbre de pago derivados de actos administrativos de gobierno. Se indica en la industria aseguradora que este tipo de productos o coberturas se creó en 1948 con el Plan Marshall, a través del cual el Gobierno de los EE.UU. promocionó con inversiones de renta variable la reconstrucción de Europa tras la II Guerra Mundial. Hoy en día esta cobertura se ha extendido a múltiples formas de inversión extranjera, destacando proyectos de financiamiento de infraestructura o de deuda externa, además de ampliarse a cubrir negocios entre privados y/o entre privados y estados, incluyendo operaciones de leasing sobre activos, financiamientos de productos o comercios y, en general, cualquier industria o mercado donde exista un riesgo de crédito.

El desarrollo del mercado financiero ha generado especial interés de inversores en naciones en vías de desarrollo o mercados emergentes. Es en esas realidades donde justamente genera mayor sentido la existencia de pólizas contra riesgos políticos especialmente considerando que logran extender cobertura a riesgos de crédito que derivan de eventos políticos tan complejos como cambios de Gobierno a través de 
elecciones o insurrecciones populares, presencia de sistemas judiciales influenciados por la política, surgimiento de movimientos populares que puedan desembocar en violencia $y$, en general, cualquier evento material que pueda generar debilidad institucional del país y, en consecuencia, aumentar el riesgo de crédito tolerable.

Cabe hacer presente que esta cobertura también incluye amparo para riesgos propios o daños físicos dado que múltiples operaciones de financiamiento se realizan sobre equipamiento, maquinaria o instalaciones que efectivamente pueden ser confiscadas, retenidas, embargadas o nacionalizadas. Por tanto, la póliza de riesgos políticos se comporta como una de crédito o financiera, cuando se trata de coberturas económicas, pero también se comporta como una póliza indemnizatoria de daño propio cuando se generan perjuicios sobre activos físicos de propiedad del asegurado y/o vinculados jurídicamente a la operación financiera asegurada.

Adicionalmente, podemos afirmar que el Seguro de Riesgos Políticos también se extiende a cubrir eventos de cierre patronal (denominado lock out), particularmente cuando este hecho deriva de eventos de violencia social tales como huelgas, disturbios, alteraciones del orden público, guerra, terrorismo y, en general, daños intencionados.

En términos de exclusiones, vemos que este tipo de seguros no cubre eventos puramente financieros de insolvencia ni tampoco eventos de incumplimiento de obligaciones que deriven de hechos puramente comerciales. En concreto, algunos condicionados particulares incluyen un catálogo no taxativo de exclusiones que contiene, entre otros, las siguientes ${ }^{15}$ :

- La falta de mantenimiento o asegurar los permisos necesarios;

- El incumplimiento de la legislación del país extranjero;

- Las fluctuaciones monetarias;

- Las fluctuaciones de los precios en los productos básicos o de primera necesidad;

- Incumplimiento de contrato por el asegurado;

- Fraude.

Por todo lo dicho, y a modo de resumen, podemos indicar que el tipo de pólizas en análisis incluye coberturas para inversiones de tipo fijo, participaciones, beneficios o ganancias acumuladas, préstamos entre empresas, dividendos a ser pagados a filiales extranjeras, stock de bienes de consumo, maquinaria, y capacidad operativa o productiva que afecte el riesgo de crédito, entre otros, incluyendo esencialmente eventos de incumplimiento de un contrato de préstamo o una prestación como consecuencia de un suceso calificable como riesgo político.

\footnotetext{
15 Estamos ocupando como referencia un condicionado ejemplo publicado por Willis Tower Watson, contenido en: Guía de Seguro de Riesgo Político para las Instituciones Financieras (2016). Recurso on-line. https://willistowerswatsonupdate.es/riesgos-corporativos-y-directivos/riesgo-politico-para-lasinstituciones-financieras/ Última visita: 12.04.2021.
} 


\section{b. Tipos de Seguros que contienen estas cláusulas y redacciones habituales}

Tal como se ha mencionado previamente, la noción de riesgo político es amplia, tanto así que no todo riesgo político se encuentra cubierto a través de un mismo tipo de seguro. Líneas atrás se indicó que existirán pólizas de riesgo político propiamente tales (caracterizadas en el punto anterior), y otras que se extienden a cubrir daños derivados de riesgos políticos de origen social. En esta sección nos enfocaremos en identificar y caracterizar estos "otros seguros" que contienen coberturas de riesgos políticos y que forman parte de la segunda categoría propuesta.

\section{i. Seguros de Crédito y Garantia}

En líneas generales, los seguros de crédito y garantía son aquellos que se extienden a proteger a las empresas en caso de no pago de cuentas por cobrar a causa de una insolvencia declarada o por créditos impagos. En general, este tipo de pólizas se pueden confundir con las pólizas de riesgo políticos propiamente tales, tanto así que, en ciertos mercados, se utilizan como si se trataran del mismo producto. Por tanto, tendremos que acudir a mercados más sofisticados para encontrar diferencias técnicas de redacción en los condicionados particulares de cobertura.

La clave para diferenciar un seguro de crédito de uno de riesgos políticos está en analizar el core de la cobertura. Así, mercados especializados nos confiman que "political risk insurance (PRI) captures most, but not all, noncommercial risks. It covers political events, including the direct and indirect actions of host governments that negatively impact investments and are not properly compensated for."16 ${ }^{17}$. En cambio, las pólizas de crédito y garantía cubren justamente riesgos comerciales de cualquier origen, salvo los que obedezcan a causas imputables a negligencia del asegurado, extendiéndose a través de cláusulas adicionales a otros no comerciales, como los riesgos políticos.

Las redacciones habituales versan del siguiente modo:

\section{Cobertura de Crédito}

Las pérdidas o deterioros netos definitivos que experimente el patrimonio del Asegurado, como consecuencia, directa e inmediata, del incumplimiento por parte del tercero del pago de las obligaciones en dinero o de crédito de dinero que se especifiquen detalladamente como cubiertas en las Condiciones Particulares de la presente póliza y a las cuales se haya obligado el tercero en el contrato o convención que, suscrito entre ese tercero y el Asegurado, forma parte integrante de la presente póliza; sujetas dichas pérdidas o deterioros al deducible obligatorio especificado en las mismas Condiciones Particulares.

\footnotetext{
16 Traducción libre: El seguro de riesgo politico (PRI) captura la mayoría, pero no todos, los riesgos no comerciales. Cubre eventos o incidentes politicos, incluidas las acciones directas e indirectas de los gobiernos anfitriones que impactan negativamente inversiones y no se compensan adecuadamente.

${ }_{17}$ Cita contenida en "World Investment and Political Risk", Multilateral Investment Guarantee Agency (MIGA), editado por el World Bank Group. Recurso on-line (Última visita: 12 de abril de 2021.): https:// www.miga.org/sites/default/files/archive/Documents/WIPR10ebook.pdf.
} 


\section{Cobertura de Garantía}

Las pérdidas en dinero que le irrogue al Asegurado el incumplimiento por parte del tercero de obligaciones provenientes del contrato o convención individualizado en las Condiciones Particulares que no deban satisfacerse directamente en dinero, que se especifiquen en las Condiciones Particulares, y siempre que ese incumplimiento sea imputable al tercero o bien provenga de causas que afecten directamente su responsabilidad.

Las versiones modernas de este condicionado separan las coberturas en pólizas de crédito y pólizas de garantía. Ya en la actual póliza de seguro de crédito global, depositada en la Comisión para el Mercado Financiero en Chile, se incluye un catálogo de eventos que se deberán entender como evento de riesgo político para efectos de la cobertura:

"2.3 Para efectos de esta Póliza se entenderá como Ocurrencia de un Riesgo Político cualquiera de las siguientes situaciones:

A) La falta de pago de todo o parte de una Deuda Asegurada no disputada por un Comprador Público Extranjero al vencerse el Plazo de Prórroga Máxima.

B) El rechazo formal e injustificado por parte de un Comprador Público Extranjero a aceptar los bienes.

C) La imposibilidad directa de realizar el pago de la Deuda Asegurada o la realización por parte del Asegurado del contrato de venta de bienes y lo prestación de servicios como resultado de cualquiera de los siguientes sucesos políticos: - La ocurrencia en el país en que el Comprador esté ubicado (siempre y cuando el Comprador no esté ubicado en el país al que pertenece el Asegurado) de una guerra (ya sea declarada oficialmente o no) a menos que lo excluya el artículo 4 de esta Póliza, invasión, actos hostiles de enemigos extranjeros, guerra civil, insurrección, rebelión, motines, revolución y/o toma militar de poder o usurpación del mismo. - La implementación de una ley o medida con fuerza de ley que prohiba la exportación de bienes o la prestación de servicios desde el país del Asegurado. - La implementación de una ley o medida con fuerza de ley que prohíba la importación de bienes o la prestación de servicios al país del Comprador. - Restricciones a las transferencias, en aquellos paises donde exista un decreto por parte del gobierno del país del Comprador imponiendo restricciones a la transferencia de moneda. - La aprobación de un decreto por parte del gobierno del país en que el Comprador está ubicado, eximiéndolo de pagar la suma adicional debido a la existencia de una diferencia entre el monto depositado en moneda local, en la fecha del depósito o en la fecha en que se completaron las formalidades de la transferencia, y el monto por pagarse. - La incapacidad de liquidar la moneda del país del Comprador, donde la deuda es pagadera, a una moneda distinta de la moneda del país del Comprador."

Como se notará, se trata de un wording o condicionado particular que toma de manera muy completa el catálogo de hechos que también es posible asegurar a través de una póliza de riesgos políticos propiamente tales. Como se dijo, la diferencia radica en que las pólizas de crédito y garantía se extienden a cubrir la insolvencia jurídica, motivada por una suspensión de pagos, quiebra o concurso mercantil, y la mora prolongada, debida a otras causas comerciales, indemnizando justamente las pérdidas financiaras con origen en incumplimientos comerciales. En ese escenario, las cláusulas de riesgos políticos, muchas veces, son adicionales ${ }^{18}$. Entendemos, entonces, que las pólizas de crédito y garantía son el género, y las pólizas de riesgos políticos son una especie.

\footnotetext{
${ }^{18}$ Como ocurre, por ejemplo, en la cláusula de riesgo político, adicional a póliza revolving de seguro de crédito depositada bajo el Código pol420140034, en la Comisión para el Mercado Financiero, Chile.
} 


\section{ii. Seguros de Incendio}

Las pólizas de incendio son aquellas en donde la materia asegurada incluye edificios y/o bienes físicos, existiendo un asegurador se obliga a indemnizar toda pérdida o daño material que sea consecuencia de la acción directa de un incendio u otro evento imprevisto, accidental y repentino, siempre que se trata de las ubicaciones amparadas en la póliza y que no se encuentre excluido por las Condiciones Particulares del seguro contratado.

Este tipo de pólizas contemplan múltiples cláusulas adicionales que pueden extender cobertura a avería de maquinaria, rotura de cristales, daños en instalaciones y equipos electrónicos, entre otros. Normalmente se incluyen entre los eventos o siniestros que se entenderán cubiertos: "e. Los daños materiales que sufran los bienes asegurados causados por caída y colisión de aeronaves, colisión de vehículos u objetos flotantes, colapso de edificio, combustión espontánea, construcción o demolición de edificios colindantes, huelga, saqueo o desorden popular, rotura de cañerías o desagues y por desbordamiento de estanques matrices"19.

En la cláusula previamente citada se lee cobertura a eventos que naturalmente son calificables como materializaciones de riesgos políticos de origen social. Más adelante, la misma póliza menciona opciones de cobertura adicional a eventos calificables como terroristas, incluidos delitos que pudieren ser calificados como contra la seguridad del estado, es decir, como una forma material de quiebre de orden público.

Finalmente, en el mismo modelo de póliza estudiado podemos encontrar una cláusula extensiva de robo, que extiende cobertura a los siguientes eventos: "4. Robos que se produzcan durante una situación anormal a causa de: i) huelga, ii) cierre o paro patronal (lock out); iii) saqueo o desorden popular; iv) actos de autoridad; v) atentados; vi) hechos que las leyes califican como delitos contra el orden público; vii) actos maliciosos".

Por tanto, podemos afirmar que a través de una Póliza de Incendio (o de robo, según sea el caso) podemos extender cobertura a otros daños físicos o materiales que pudieren tener como origen riesgos políticos de naturaleza social.

\section{iii. Seguros de Huelga y Pérdidas por Paralización}

Normalmente este tipo de seguro se comercializa como adicional al seguro de incendio o robo, de hecho, se establece como causa directa de cobertura el que haya existido, a modo de precedente, un hecho calificable de incendio y que se encuentre cubierto en dicha póliza. Esto lo extraemos de la póliza que estamos usando de base para el análisis, donde se lee: "La compañía indemnizará los perjuicios por la paralización que el asegurado sufra durante el período definido por este seguro, como consecuencia de la ocurrencia de un incendio u otro riesgo adicional cubierto por la póliza de incendio sobre bienes físicos individualizada en las condiciones particulares de este contrato a la cual se asocia o adiciona. Es condición para que exista un perjuicio indemnizable

\footnotetext{
19 Artículo 2, materia asegurada, en POL: Póliza de Seguro de Incendio y Multiriesgos para empresas, Incorporada al Depósito de Pólizas de la Comisión para el Mercado Financiero (CMF), bajo el código POL120160181.
} 
con cargo al presente seguro, que haya ocurrido un siniestro cubierto por el seguro de incendio sobre bienes físicos referido en el respectivo condicionado particular ${ }^{20}$ ".

Es decir, si el hecho que precede a la paralización es, en el ejemplo, un incendio ocurrido por alguna forma de desorden popular, aquella pérdida financiera se encontrará cubierta por este seguro.

\section{iv. Seguros maritimos y de comercio internacional.}

Actualmente el comercio internacional se puede materializar de diversas maneras, pero es el transporte la variable que mayor efecto produce en dicha concreción. Dentro de las opciones de transporte se estima que el marítimo concentra el 90\% del comercio mundial y, en esa línea, la Organización Marítima Internacional (OMI) ha señalado que el transporte marítimo es "el vehículo del comercio mundial", reforzando con esas palabras la idea de que los gobiernos, las organizaciones públicas y privadas del sector y, en general, todas las partes interesadas, deben actuar en función de proteger dicha importancia por ser el método más económico, seguro y respetuoso con el medio ambiente para el transporte de mercancías en todo el mundo ${ }^{21}$.

Es por lo anterior que dedicaremos algunas líneas a los seguros marítimos para efectos de entender su contenido respecto de aquellos riesgos de origen político. Resulta relevante indicar que son múltiples los seguros que inciden en el transporte marítimo, encontrando pólizas de casco y maquinarias; póliza de transporte de mercancías; pólizas de fletes y desembolsos; coberturas de responsabilidad y coberturas de seguros P\&I (aquellos otorgados por los clubes de indemnidad y protección), entre otros. Para efectos del presente análisis, y atendido que es nuestro interés comprender qué cobertura existe para aquellos riesgos ya definidos, es que analizaremos el seguro marítimo como una generalidad, y lo describiremos como aquel que se extiende a cubrir los riesgos inherentes a la navegación, tal como lo describe el profesor BARROILHET ${ }^{22}$.

En la misma línea descrita, el Art. 1161 del C. de Com. de Chile dispone: "Por regla general, los seguros maritimos tienen por objeto indemnizar al asegurado respecto de la pérdida o daño que pueda sufrir la cosa asegurada por los riesgos que implica una aventura marítima, fluvial, lacustre, o en canales interiores." Dada la definición, entendemos que para la realidad del comercio marítimo existirán tantas formas de riesgos como la que existen para otras industrias. Así, por ejemplo, una de las clasificaciones que ofrece el profesor BARROILHET distingue entre los riesgos marítimos desde el punto de vista de la habitualidad, identificando riesgos ordinarios, riesgos de guerra y políticos, y riesgos adicionales ${ }^{23}$.

\footnotetext{
${ }^{20}$ En Título primero, descripción de la cobertura. Póliza de Seguro de Perjuicios por Paralización, Incorporada al Depósito de Pólizas de la Comisión para el Mercado Financiero (CMF), bajo el código POL120130174.

${ }^{21}$ Opazo, Marco (2006) "El transporte marítimo mundial". Publicación de Revista Negocios Globales y Logística. Recurso on-line: http://www.emb.cl/negociosglobales/articulo.mvc?xid=1390. Última visita: 12 de abril de 2021.

22 Barroilhet A., Claudio, (2016). "Derecho Marítimo". Editorial Librotecnia. Santiago, Chile, pp. 628 y ss. ${ }^{23}$ Ob. Cit. No24., p. 657.
} 
Sin embargo, en la generalidad, los riesgos podrán ser aquellos naturales del contrato de seguro marítimo y aquellos riesgos accidentales. Debemos entender por riesgos naturales del contrato de seguro marítimo aquellos descritos en el art. 1162 inciso segundo del C. de Com. de Chile, y que incluye los peligros que provengan de la navegación, mencionando algunas situaciones especiales tales como aquellas que derivan de las condiciones del tiempo, el incendio, la presencia de piratas, ladrones, asaltantes, capturas, entre otros. Se distinguen los riesgos naturales del contrato de seguro marítimo de aquellos accidentales por ser, estos últimos, incorporados a la cobertura previo acuerdo expreso de las partes. De hecho, otorga esta prerrogativa el mismo art. 1163, indicándose que a través de cláusulas adicionales se pueden cubrir hechos derivados de guerra, huelgas, terrorismo o actos maliciosos, entre otros. Estos últimos eventos son aquellos que corresponden a riesgos políticos y que, en nomenclatura maritimista, se identifican como riesgos accidentales del contrato de seguro marítimo.

Cabe hacer presente que los riesgos previamente identificados no son propiamente marítimos, pero son una realidad que choca habitualmente con el comercio marítimo, como cuando existen paralizaciones portuarias que impiden el ingreso o despacho de naves. Dada esta realidad es que tanto la huelga como la guerra se encontrarán normalmente excluidas de los seguros marítimos, debiéndose contratar como cláusulas adicionales, siendo esa la única manera de conseguir la cobertura. Es decir, no se trata de riesgos que puedan encontrar cobertura tácita, dado que siempre requerirán acuerdo expreso y mención a través de cláusulas adicionales. Misma situación ocurre con el terrorismo, los actos maliciosos o actos políticos.

\section{c. Tipos de proveedores de Seguros de Riesgos politicos}

Tal como hemos venido describiendo, las coberturas para riesgos políticos se pueden contratar a través de diversas vías. La manera más común será lograr adquirir estas coberturas a través de Compañías de Seguros especializadas en seguros de crédito y caución. Esta será la forma a través de la cuál logremos cobertura de seguros de riesgo político propiamente tal o de seguros de crédito y garantía con adicionales que se extienden a amparar riesgos políticos. A través de estos proveedores lograremos diseñar pólizas que valoricen correctamente la noción de riesgo financiero que se asocie al proyecto o contrato que se busca asegurar.

Otra vía será a través de Compañías de Seguros Generales, pero esta línea de suscripción resulta recomendable para aquellos asegurados que busquen cobertura de daños materiales o físicos derivados de riesgos políticos, incluidas aquellas pérdidas financieras derivadas de la paralización.

\section{DESAFÍOS PARA LA INDUSTRIA}

\section{a. Perspectiva General}

Tal como hemos venido señalando, los riesgos políticos (en el sentido y alcance que ya hemos presentado) son una realidad que, a pesar de la globalización y el sentido 
de uniformidad acentuado por las relaciones internacionales entre las naciones, se puede categorizar o, al menos, identificar a través de herramientas cuantitativas y cualitativas que aportan conclusiones que son esenciales para la suscripción de estos riesgos (sea a través de pólizas de riesgos políticos propiamente tales o a través de pólizas diversas con cláusulas adicionales que extienden cobertura a estos riesgos).

Es así como actores relevantes de la industria aseguradora han diseñado Mapas de Riesgo Político que permiten identificar naciones o regiones con indicadores de mayor o menor estabilidad dependiendo de la propensión a la ocurrencia de eventos que produzcan incertidumbre económica y política. A modo de ejemplo, Marsh McLennan, Broker global, cuenta con una plataforma ${ }^{24}$ de actualización que provee la siguiente información:

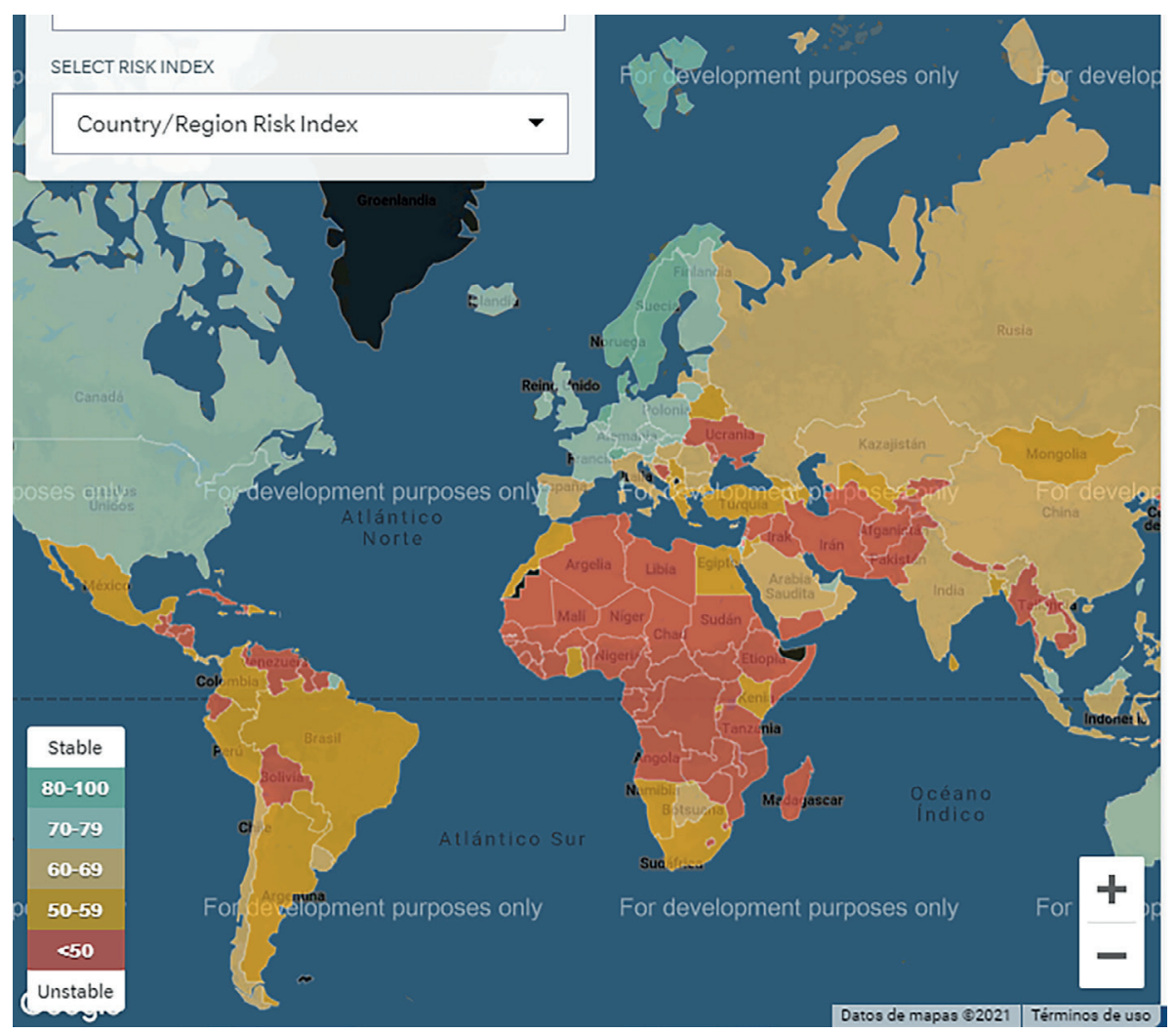

Imagen n¹: Mapa de Riesgo Político Mundial, 2020. Visión general

La imagen $n^{\circ} 1$ permite identificar a través de un factor de estabilidad la posición global de una nación o de una región. Así, por ejemplo, vemos en el África se encuentran

\footnotetext{
${ }^{24}$ Imagen obtenida del "Mapa de Riesgo Político 2020: Tensiones comerciales amenazan la estabilidad política". Informe técnico emitido por Marsh McLennan. Recurso on-line. Última visita: 12 de abril de 2021. https://www.marsh.com/cl/es/insights/research/political-risk-map-2020.html
} 
naciones con factor de riesgo mayoritariamente $<50$, tal como Chad, país de África Central, que posee la siguiente reseña de riesgo: "Chad will continue to face political instability in 2020. President Idriss Déby - in office since 1990 - is likely to remain in power in the coming year. Although an election is due to be held in 2020 for the National Assembly, it is unlikely that his party - which holds almost two-thirds of the seats - will lose its overall majority. This should ensure broad policy continuity in the short term. Despite this, social instability will remain a threat as pressure on government finances from lower global oil prices (oil being a major source of government revenues) will continue to drive reductions in state spending. This may contribute to an elevated risk of public sector strikes, which have been prominent in 2019. Chad also faces major security risks from rebel Chadian armed groups based in Libya, as well as Islamist groups entrenched around Lake Chad."

En contraposición, encontramos la realidad de Botswana, país de África Austral, que se presenta como el más estable de la región, con la siguiente reseña: "Botswana will remain one of Africa's most stable countries. Despite gradually waning popular support, the ruling Botswana Democratic Party (BDP) increased its share of the seats in the National Assembly from 43 to 44 following the October 2019 general election. The vote was held peacefully, and risks to social stability remain low in the short term".

En la industria financiera estas formas de análisis no son aisladas, de hecho, importantes actores, como Ernst \& Young (EY) generan anualmente un listado con los eventos que presentan mayor probabilidad de proveer inestabilidades para el escenario económico mundial. Es así como para el 2021 identifican los siguientes acontecimientos como los más importantes para el escenario de riesgo político global ${ }^{25}$ :

Geopolítica de COVID-19

Desenredando la interdependencia entre EE.UU. y China

Hacia una autonomía estratégica europea

EI neo-estatismo en aumento

Revitalizar las agendas de política climática

Geopolítica de la tecnología y los datos

Reajuste de la política de los Estados Unidos

Punto de inflexión para la deuda de los mercados emergentes

La dinámica geopolítica en el Indo-Pacífico

Otra ola de disturbios sociales

\footnotetext{
25 "Implicancias de los elevados niveles de riesgo político para las empresas en 2021", informe técnico emitido por la división de estudio y análisis de riesgos políticos de Ernst \& Young Global Limited (EYG). Recurso on-line (Última visita: 12 de abril de 2021). https://www.ey.com/es_cl/geostrategy/what-elevatedlevels-of-political-risk-mean-for-business-in-2021
} 
Justamente el concepto "geopolítica" (o geografía política), en tanto forma de analizar la vida global y las relaciones entre naciones, se presenta como un concepto esencial en el listado previamente citado, lo anterior viene a reforzar la idea práctica de que existe un riesgo muy vinculado a los gobiernos, la toma de decisiones y la elaboración de estrategias políticas, que ciertamente puede incidir de manera directa en la estabilidad financiera global.

Debemos además considerar que, así como existen factores de riesgo nacionales o regionales, existe también un score que viene a fijar un rating anual de riesgo político mundial. De hecho, este "factor" global de riesgo político, según analistas, habría alcanzado su máximo histórico durante el 2020 por eventos de tensión entre EE.UU. y China derivados de conflictos en la zona mediterránea Oriental. Así se grafica la evolución de este factor de riesgo global:

Global political risk reached a multiyear high in 2020

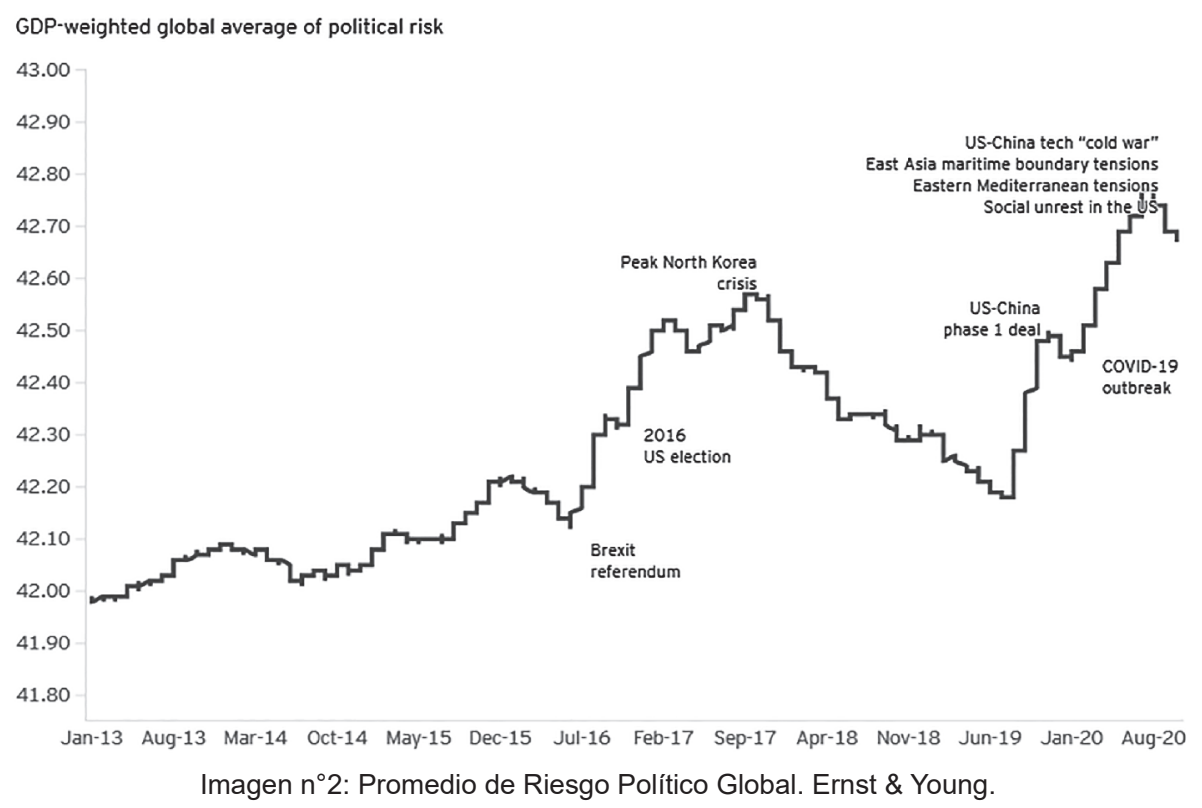

\section{b. Perspectiva desde la Industria Aseguradora}

Desde la perspectiva de la transferencia de riesgos, asegurar incidencias o siniestros derivados de eventos calificables como concreciones de riesgos políticos plantean múltiples desafíos.

En primer término, exige a la industria aseguradora y a los suscriptores una revisión constante de la situación política y social de cada país. Para estos análisis son de mucha ayuda los reportes de estabilidad geopolítica global que se emiten año, resultando especialmente relevante la opinión de los analistas de riesgos financiero que son quienes finalmente traducen en nomenclatura aritmética (un rating o score 
de riesgo) los eventos sociales o políticos que puedan estar ocurriendo en diversas latitudes y que tengan la aptitud de representar un riesgo potencial. Muy relevante es este análisis para los mercados emergentes que son cada vez más atractivos para las inversiones de gran envergadura.

En segundo término, existe una constante actualización de lo que se va a entender como caso fortuito o fuerza mayor en cada mercado. $\mathrm{Y}$ esto radica en que ciertos hechos, dado lo que se defina como normal o habitual, pueden pasar de ser aislados en el tiempo a recurrentes. Jurídicamente esa transformación implica pasar de entender un evento como aislado, y propio de aquellos que entendemos como evento de fuerza mayor, a uno de común ocurrencia y, por tanto, que requiere cobertura adicional.

De conformidad con lo dispuesto en el artículo 45 del Código Civil de Chile, se llama fuerza mayor o caso fortuito el imprevisto a que no es posible resistir como un naufragio, un terremoto, los actos de autoridad ejercidos por funcionarios públicos, entre otros. Por tanto, existirán casuísticas, tales como un "estallido social", siguiendo con el ejemplo chileno, que terminen por transformar ese hito en algo previsible y ya no eventualmente definible como propio de los hechos de fuerza mayor. Es decir, podremos tener nuevos hechos que serán imposibles de resistir pero previsibles.

En un tercer aspecto, derivado del punto anterior, consiste en que la industria aseguradora deberá necesariamente efectuar completas revisiones de las pólizas que comercializan y sus condiciones de cobertura en atención a la aparición de nuevos riesgos que podrían ser entendidos como excluidos o excluibles, o, por el contrario, nuevos hechos que pueden ser cubiertos pero mediante la incorporación de cláusulas adicionales redactadas para tales efectos, tal como comentamos respecto de los riesgos accidentales en el seguro marítimo.

Y en un cuarto aspecto, no menos relevante, la nueva realidad geopolítica global exige actualizar los mecanismos de suscripción a fin de proveer procedimientos efectivos para que los asegurados declaren completa y oportunamente su relación con aquel nuevo factor de agravación que pudiera ser detectado en el contexto del riesgo político nacional o regional.

\section{CONCLUSIONES}

Es inevitable concluir que para la industria aseguradora cada nuevo hecho, por negativo que sea, constituye una oportunidad comercial. Así, nos encontramos con seguros de daño propio que normalmente incluyen cobertura para daños físicos derivados de riesgos políticos que hoy han pasado a ocupar una nueva posición de interés comercial dados los cambios geopolíticos que el mundo está viviendo.

Actualmente existe una nueva relevancia práctica de clausulados o redacciones que hasta hace poco parecían estándar, pero que ahora ponen en riesgo la estabilidad de grandes transacciones. Esto es muy similar a lo que ocurre con realidades que hasta hace poco eran una proyección de futuro pero que actualmente ya generan pérdidas en caso de ocurrencia, como los riesgos cibernéticos y sus nuevas formas de cobertura. 
En concreto, todo lo que hemos expuesto respecto de los riesgos políticos y sus manifestaciones demuestran que la industria aseguradora debe hacer múltiples esfuerzos técnicos para asegurar el correcto control y seguimiento de las realidades políticas de las naciones donde mantienen operaciones. Y, desde la vereda del asegurado, exige un análisis profundo en términos de valorar correctamente las variables propias de la estabilidad normativa, regulatoria o legal en aquellos mercados donde, junto con existir un atractivo comercial, existe un mayor riesgo financiero.

Finalmente, podemos confirmar que existen diversas formas de cobertura para riesgos políticos, pero resulta esencial analizar cuidadosamente las estructuras de coberturas y exclusiones puesto que múltiples pólizas exigen declaraciones especiales y/o cláusulas adicionales para cubrir efectivamente daños propios, físicos o financieros derivados de la materialización de riesgos políticos.

\section{BIBLIOGRAFÍA}

\section{Normas Juridicas Chilenas}

Constitución Política de la República de Chile. (CPR)

Código Civil de Chile. (C. C.)

Código de Comercio de Chile. (C. de Com.)

D.L. N³538, de 31 / 05 / 1978 que "Sustituye la ley de navegación marítima".

Libros, Artículos y/o Capítulos de Libros.

Barroilhet A., Claudio (2016). "Derecho Marítimo”. Editorial Librotecnia. Santiago, Chile.

Bermúdez S. Jorge (2005). "El principio de confianza legítima en la actuación de la administración como límite de la potestad invalidatoria". Revista de Derecho Vol. XVIII - N² 2 - Diciembre, 2005, pp. 83-105. Santiago, Chile.

CARvajal A., Lorena y MAYer L., Laura (2015) El Nuevo Fraude de Seguros. Artículo académico, Revista de Derecho de la Universidad Católica del Norte, Chile, pp. 280 y ss.

MÁrquez G. Stephanie. (2009). "El Orden Público y su función como límite a la eficacia, reconocimiento y ejecución de los laudos arbitrales internacionales en Chile”. Tesis para optar a grado de Magíster. Universidad de Chile. Santiago, Chile. Recurso disponible on-line, en: http://repositorio.uchile.cl/bitstream/handle/2250/110957/demarquez_s.pdf;sequence=1. Última visita: 10.04.2021.

Morales T., Paola (2005). "Political Risk Insurance and Breach of Contract Coverage: How the Intervention of Domestic Courts May Prevent Investors from Claiming Insurance". Pace International Law Review, Vol. 17, issue II, fall 2005, pp. 303-345.

Ríos Ossa, Roberto (2010). "Modificación al Código de Comercio Chileno: Artículo 513 inciso segundo -El Riesgo-". Revista Chilena de Derecho, vol. 37 N³, pp. 505-520. Santiago, Chile. 
Ríos URzÚA, Vicente (2017). "Noción de riesgo asegurable: la importancia de identificar un riesgo atípico”. Revista Chilena de Derecho de Seguros, Año 19, º 26, pp. 99-112. Santiago, Chile.

Roldán P. Juan F. (2010). “El estado del arte del concepto de Orden Público Internacional en el Ámbito del Derecho Internacional Privado y el Arbitraje Internacional”. Revista de Derecho Privado N 44, Julio - Diciembre de 2010. Universidad de los Andes, Bogotá Colombia.

Roncancio J., Germán (2014). “Contexto Geopolítico, Globalización, Crisis Civilizatoria y Paz en Colombia”. Artículo de Investigación, publicado en El Ágora USB, Universidad de San Buenaventura Medellín. V. 14, No 2, Junio - Diciembre, pp. 437450. Medellín, Colombia.

\section{Libros de consulta general}

Contreras S., Osvaldo (2002). "El Contrato de Seguros". Editorial Jurídica. Santiago, Chile.

VÁsQuez P., María Fernanda (2019). "Contrato de Seguros: Doctrina y Jurisprudencia”. Editorial Tirat lo blanch. Valencia, España.

\section{Modelos de Pólizas}

Póliza de Seguro de Crédito y Garantía para contratos en general y de ejecución inmediata, Inscrita en el Registro de Pólizas bajo el código POL 191 034, SVS, Chile.

Póliza de Seguro de Crédito y Garantía, Inscrita en el Registro de Pólizas bajo el código POL 1 91035 , SVS, Chile.

Póliza de Seguro de Crédito Global, Incorporada al Depósito de Pólizas de la Comisión para el Mercado Financiero (CMF), bajo el código POL420140186

Póliza de Seguro de Incendio y Multiriesgos para empresas, Incorporada al Depósito de Pólizas de la Comisión para el Mercado Financiero (CMF), bajo el código POL120160181.

Póliza de Seguro de Perjuicios por Paralización, Incorporada al Depósito de Pólizas de la Comisión para el Mercado Financiero (CMF), bajo el código POL120130174

Cláusula de Riesgo Político, adicional a póliza revolving de seguro de crédito, Incorporada al Depósito de Pólizas de la Comisión para el Mercado Financiero (CMF), bajo el código POL420140034.

Political Risk Insurance Policy, HDFC ERGO General Insurance Company Limited.

\section{Otros documentos y artículos electrónicos:}

"Guía de Seguro de Riesgo Político para las Instituciones Financieras", (2016). Recurso online. https://willistowerswatsonupdate.es/riesgos-corporativos-y-directivos/riesgopolitico-para-las-instituciones-financieras/ Última visita: 12 de abril 2021.

"Implicancias de los elevados niveles de riesgo político para las empresas en 2021", informe técnico emitido por la división de estudio y análisis de riesgos políticos de Ernst \& Young Global 
Limited (EYG). Recurso on-line (Última visita: 12 de abril de 2021). https://www.ey.com/ es_cl/geostrategy/what-elevated-levels-of-political-risk-mean-for-business-in-2021

"Informe de Perspectivas de la Economía Mundial", enero 2021. Fondo Monetario Internacional. Recurso on-line. URL: https://www.imf.org/es/Publications/WEO/ Issues/2021/01/26/2021. Última visita: 09 de abril de 2021.

"Mapa de Riesgo Político 2020: Tensiones comerciales amenazan la estabilidad política". Informe técnico emitido por Marsh McLennan. Recurso on-line. Última visita: 12 de abril de 202021. https://www.marsh.com/cl/es/insights/research/political-riskmap-2020.html

"World Investment and Political Risk", Multilateral Investment Guarantee Agency (MIGA), editado por el World Bank Group. Recurso on-line (Última visita: 12 de abril de 2021.): https:/www.miga.org/sites/default/files/archive/Documents/WIPR10ebook.pdf. 